Pedagogía y Saberes n. ${ }^{\circ} 54$

Universidad Pedagógica Nacional

Facultad de Educación. 2021. pp. 9-21

\title{
El laberinto comeniano o el anhelo de una gran transformación social (1623)
}

\section{The Commenian Labyrinth or the Longing for a Great Social Transformation (1623) \\ O Labirinto Comeniano ou o desejo de uma grande transformação social (1623)}

María Esther Aguirre*

Aguirre, M. (2021). El laberinto comeniano o el anhelo de una gran transformación social (1623). Pedagogía y Saberes, (54). https//doi.org/10.17227/pys.num54-11580

* Doctora en Pedagogía por la Facultad de Filosofía y Letras de la UNAM, ha realizado estudios de Historiografía francesa en el Instituto de Investigaciones Dr. José María Luis Mora y una estancia de dos años en la Università degli Studi di Firenze. Correo: mariaestheraguirre@gmail.com 


\title{
Resumen
}

Juan Amós Comenio (Uherský Brod, 1592-Ámsterdam, 1670) es uno de los autores recurrentes en los estudios educativos, del que se han exaltado las aportaciones en el ámbito de la didáctica en clave positiva, en forzadas interpretaciones propias de una modernidad avanzada. Comenio, su obra y sus andanzas forman parte de la compleja topología del itinerario seguido en los siglos XVI y XVII por otros muchos de sus interlocutores en la construcción de un espacio intelectual propio empeñado de tal modo en acuñar otros saberes, otras relaciones, otras instituciones, otros mundos, a la vez no logra, ni desea, sacudirse las propias historias para construir unas nuevas. Aproximarnos a las aportaciones de los pensadores que contribuyeron a configurar el ordenamiento social y cultural de la modernidad, a través de obras que den cuenta de otras facetas que las ya tradicionalmente fijadas, permite acercarnos, no sin sorpresa, al sentido de la vida, a los Axis mundi que plantea Eliade, desde el cual ordenan el mundo y su actuación en él, sentido al que no escapan la reforma total de los saberes y de los haceres en cuestión. Tal es el propósito de este artículo: explorar algunos sentidos del cultivo de las imágenes laberínticas y analizar ciertos aspectos simbólicos de la alegoría comeniana El laberinto del mundo (1623) desde la perspectiva de los procesos de transformación interior y de la reforma social, ad hoc para los momentos de incertidumbre, de quiebre del modelo neoliberal, de indicios de un nuevo orden social que comienza a vislumbrarse y, hoy por hoy, nos confrontan e impelen a reflexionar las perspectivas de una mayor calidad de vida para todos.

\section{Palabras clave}

reordenamiento social; imágenes laberínticas; hermenéutica simbólica; mundo comeniano; pensamiento utópico

\begin{abstract}
John Amos Comenius (Uherský Brod, 1592-Amsterdam, 1670) is one of the recurring authors in educational studies, whose contributions in the field of didactics have been praised in a positive key, in forced interpretations of an advanced modernity. Comenius, his work and his adventures are part of the complex topology of the itinerary followed in the sixteenth and seventeenth centuries by many of his interlocutors in the construction of his own intellectual space, thus engaged in coining other knowledge, other relationships, other institutions, other worlds, at the same time does not manage, nor does it wish, to shake off their own stories to build new ones. Approaching the contributions of the thinkers who contributed to shaping the social and cultural order of modernity, through works that account for other facets than those traditionally established, allows us to approach, not without surprise, the meaning of life, to the Axis mundi proposed by Eliade, from which they order the world and their actions in it, a sense to which the total reform of the knowledge and practices in question does not escape. Such is the purpose of this article: to explore some senses of the cultivation of labyrinth images and to analyze some symbolic aspects of the Commenian allegory The Labyrinth of the World (1623) from the perspective of the processes of internal transformation and social reform, ad hoc for moments of uncertainty, of the breakdown of the neoliberal model, of signs of a new social order that is beginning to emerge and, today, they confront us and encourage us to reflect on the prospects for a better quality of life for all.
\end{abstract}

\section{Keywords}

social rearrangement; labyrinth images; symbolic hermeneutics; Commenian world; utopian thought

\section{Resumo}

Jan Amos Komensky (Uherský Brod, 1592-Amsterdam, 1670) é um dos autores recorrentes em estudos educacionais, cujas contribuições no campo da didática foram elogiadas de maneira positiva, nas interpretações forçadas de uma modernidade avançada. Comenius, seu trabalho e suas aventuras, fazem parte da complexa topologia do itinerário seguida nos séculos XVI e XVII por muitos de seus interlocutores na construção de seu próprio espaço intelectual empenhado em cunhar outros conhecimentos, outras relações, outras instituições, outros mundos, ao mesmo tempo não consegue, nem deseja, sacudir suas próprias histórias para construir novas. Abordar as contribuições dos pensadores que contribuíram para moldar a ordem social e cultural da modernidade, através de obras que explicam outras facetas além das tradicionalmente estabelecidas, permite-nos abordar, sem surpresa, o sentido da vida, o Axis mundi proposto por Eliade, do qual eles ordenam o mundo e suas ações nele, um sentido ao qual não se escapa a reforma total dos conhecimentos e práticas em questão. Esse é o objetivo deste artigo: explorar alguns sentidos do cultivo de imagens de labirinto e analisar alguns aspectos simbólicos da alegoria comeniana $O$ Labirinto do Mundo (1623) a partir da perspectiva dos processos de transformação interna e reforma social, ad hoc por momentos de incerteza, de colapso do modelo neoliberal, de sinais de uma nova ordem social que começa a surgir e, hoje, eles nos confrontam e nos incentivam a refletir sobre as perspectivas de uma melhor qualidade de vida para todos.

\section{Palavras-chave}


El misterio se experimenta, se respeta, se introduce en la vida personal. Un misterio que pueda despejarse con una explicación nunca habrá sido tal.

Romano Guardini, Persona e personalitá. Morcelliana, p. 33

¿Dónde se oculta aquello que una vez fue esperanza, y que acaso todavía lo sea, o bien pueda empezar a serlo un día? [...] ¿Cuál es el mundo que uno creyó poder tener?

HANS Blumemberg, Die Lesbarkeit der Welt. Suhrkamp, p. 10 .

\section{Introducción}

El pensador moravo Juan Amós Comenio (Nivnice, Uherský Brod, 1592-Ámsterdam, 1670), si bien es constantemente mencionado en distintos campos disciplinares, no necesariamente ha sido estudiado en forma directa, pues su obra, escrita en checo y en latín, escasamente se había traducido al español hasta décadas recientes. El más difundido de sus escritos entre nuestros círculos de estudiosos de la educación continúa siendo, sin lugar a dudas, la Didáctica magna, en la versión del jurista español Saturnino López, publicada en Madrid por la Editorial Reus en 1922, que sirvió de base para ediciones posteriores en lengua española (1971). ${ }^{1}$ En años recientes, en el mundo de habla hispana, también se tradujeron la Pampedia (1992), El mundo en imágenes (1993), El laberinto del mundo y el paraíso del corazón (1999). Esta última tuvo una nueva edición en el 2009, antecedida por la edición argentina del 2006, cuya publicación forma parte de un proyecto más amplio del Ekumene Comenius Cultural Center en Buenos Aires, Argentina.

Si bien nuestro autor ha sido conocido sobre todo por sus escritos acerca de la enseñanza, en realidad su obra cimera se refiere a la reforma de la sociedad y los saberes, mediada por la consigna de educar a todos los seres humanos en todo, totalmente. Por otra parte, incursiona en diversas temáticas, con la versatilidad propia de los tiempos; rebasa los cuatrocientos folios referidos a física, cosmografía, medidas para controlar epidemias, política, literatura, teatro, lingüística, didáctica, teoría educativa, teología, historia religiosa, mecánica y otros temas más. Así, se puede hablar de diversos tipos de escritos: teológico-filosóficos, consolatorios, sobre la historia de su comunidad

1 Desafortunadamente en esta edición se omite el "Prefacio", que aporta claves que esclarecen el sentido de la obra en su tiempo (véase Aguirre, 2001). religiosa (la Unitas Fratrum), relacionados con la reforma social y con la nueva ciencia de ese tiempo, pedagógicos y didácticos.

Sin embargo, las dificultades para acceder a la lectura directa de su obra no derivaron solo de la escasez de traducciones al español y su sucesiva publicación. También hay que tomar en cuenta que muchos de sus escritos se perdieron en medio de las guerras de religión de los siglos XVI y XVII. Otro de los factores que tuvo en contra fue la crisis de paradigmas vinculados con el surgimiento del pensamiento ilustrado y con la racionalidad cartesiana: el enciclopedista Bayle (1740), solo por dar un ejemplo, en su Dictionnaire exacerba la polémica referida a sus creencias milenaristas y sus vínculos con los profetas de la región, señalando mordazmente el "humo quiliástico" que lo rodeaba; con René Descartes, tampoco se entendió. Solo a partir del siglo XIX un movimiento iniciado por Herder desde la perspectiva del romanticismo posibilitará la relectura del pensador y de sus aportaciones al campo de la educación y de las ciencias humanas en general. Por último, también hay que considerar las obras que normalmente eran permitidas y circulaban en las regiones de creencias religiosas católicas y las propias de las Iglesias evangélicas en América.

No obstante las dificultades, la influencia de Comenio rebasa, con creces, su tiempo. Hay una línea de legados comenianos, poco visibilizada, que podemos rastrear a lo largo del siglo XIX a través del educador suizo Johann Heinrich Pestalozzi (1746-1827) referida a la creación de ambientes escolares más amables y afectuosos, a la importancia de la sensopercepción como fundamento de la intervención del maestro, con el papel de la madre en la educación de los hijos. Friedrich Froebel (1782-1852), por su parte, fue discípulo de Pestalozzi, y a él se le reconoció formalmente el establecimiento del kindergarten, institución que recoge algunas reflexiones ya planteadas por Comenio en su Informatorium školy mateřské (1632) y en Schola Ludus (Sárospatak, 1653-1654). Es de Pestalozzi de donde Froebel retoma la metáfora del educador como jardinero, que va más allá y remonta a Comenio, quien establecía un parangón entre el niño y la planta, que habría de ser atendido y cuidado para crecer en el mejor mundo posible (Aguirre, 2016, 2019).

\section{El pensador}

Comenio forma parte de las generaciones de pensadores que en los siglos XVI y XVII se abocan a la construcción de grandes sistemas de pensamiento en distintos campos del conocimiento. Así son contemporáneos Bacon (1561-1626), Galileo (1564-1642), Descartes 
(1596-1650), Giordano Bruno (1548-1600), Newton (1642-1747), Leibniz (1646-1716), entre otros. Entre ellos se dan coincidencias interesantes en relación con otras formas de pensamiento; son sensibles a las tradiciones alquímicas, al gnosticismo, al milenarismo, lo cual, a más de uno, le acarreó persecuciones de distinto tipo.

Por otra parte, Comenio es ante todo un reformador religioso comprometido con la restauración de la Iglesia, de la sociedad, del género humano, de los saberes. Forma parte de la Unitas Fratrum, Hermandad Morava que deriva de los husitas moderados y tiene diferencias importantes que la definen en relación con otras Iglesias disidentes: no fue aliada de los príncipes, como Lutero (1483-1546), tampoco portavoz de las ciudades burguesas, como Zwinglio (1484-1531) y Calvino (1509-1564); fue distante de los disidentes radicales, como Münzer (1490-1525), a pesar de lo cual su comunidad estará próxima a calvinistas y luteranos.

Como teólogo y filósofo de la Hermandad, recoge las tradiciones de místicos y neoplatónicos renacentistas, tales como Agustín de Hipona (354-430), Nicolás de Cusa (1401-1464), Pico della Mirandola (1463-1494), Justus Lipsius (1547-1606), Robert Fludd (1574-1637), Jakob Böhme (1575-1624), entre otros. Su experiencia como maestro la gesta en las escuelas de la Hermandad, dando clases de latín en las Escuelas de Gramática y como director de la Escuela en Leszno. Estuvo en contacto, ya sea directo o bien a través del estudio de sus escritos, con aquellos pensadores que ofrecían una forma novedosa de pensar las prácticas educativas, como fue el caso de Luis Vives (1492-1540), Philippe Melanchton (1497-1560), Pierre de la Rameé (1515-1572), Michel de Montaigne (1533-1592), Wolfgang Ratke (1571-1635), Charles Hoole (1610-1667) y Elias Bodin (1600-1650).

Comenio como hombre barroco (Echeverría, 1988) vive permanentemente en el umbral de la crisis tanto en lo personal como en lo social, siente en carne propia el resquebrajamiento del orden social, del mundo feudal, de la Iglesia: nacer en Moravia, ubicada en el centro del Sacro Imperio Romano Germánico, equivalía a experimentar las vicisitudes de una región codiciada por su carácter estratégico, pues el rey de Bohemia tenía un papel decisivo en la elección del emperador, lo que motivó que desde tiempos de Felipe II se fuera fortaleciendo el dominio político-religioso de los Habsburgo en la región, con la consecuente catolización de la población y el asedio, cada vez más agudo, hacia la Iglesia checa reformada. Desde muy joven fue testigo del drama de su sociedad
Esta situación de origen, conflictuada y complejizada con el avance del siglo, pesará sobre la vida de Juan Amós: desde sus primeros años, hacia 16051606, presencia la invasión de su tierra por las tropas húngaras que queman Strážnice, ciudad donde estudiaba por ese entonces; vive la Guerra de los Treinta Años (1618-1648), el inicio de la guerra civil en Inglaterra, la pugna entre esta nación y Holanda por el dominio de los territorios ultramarinos hacia 1652 y 1664, así como la invasión polaca de Leszno (1656). Todo ello lo impele a una condición permanente de exiliado: huye de las persecuciones derivadas del vasto programa de catolización puesto en marcha contra los disidentes desde 1621, abandona Fulnek y termina por alejarse definitivamente de su patria para vivir en Polonia, en Suecia, en Prusia, en Ámsterdam, donde, desde 1656, pasará el resto de su vida.

En fin, del compromiso asumido de por vida con la gran restauración de los hombres, de las sociedades, de los saberes, surgió su obra más importante, la Consulta universal para la enmienda de los asuntos humanos, organizada en siete libros, que si bien fue escrita entre 1644 y 1670, solo se descubrió y se publicó en 1966.

\section{La obra}

El laberinto del mundo forma parte de las creaciones literarias de los siglos XVI y XVII cuyo argumento, que se repite y asume diferentes soluciones en manos de cada autor, recoge las antiguas concepciones que imaginan al mundo como ciudad, y al hombre como peregrino que lo transita en pos de su destino final, trascendente. Podemos citar como ejemplo una de las obras ampliamente difundidas, Le Théâtre du Monde, où il est fait un ample discours des miserees humaines, escrita alrededor de 1556 por Pierre Boaistuau de Launai, que narra las miserias humanas en el contexto de París. En 1589 F. Lauren la tradujo al latín con el título Theatrum mundi minoris sive humanae calamitatis oceanus, y Natanael Vodnanský lo hizo al checo en 1605 (Czyzevsky, 1953). 


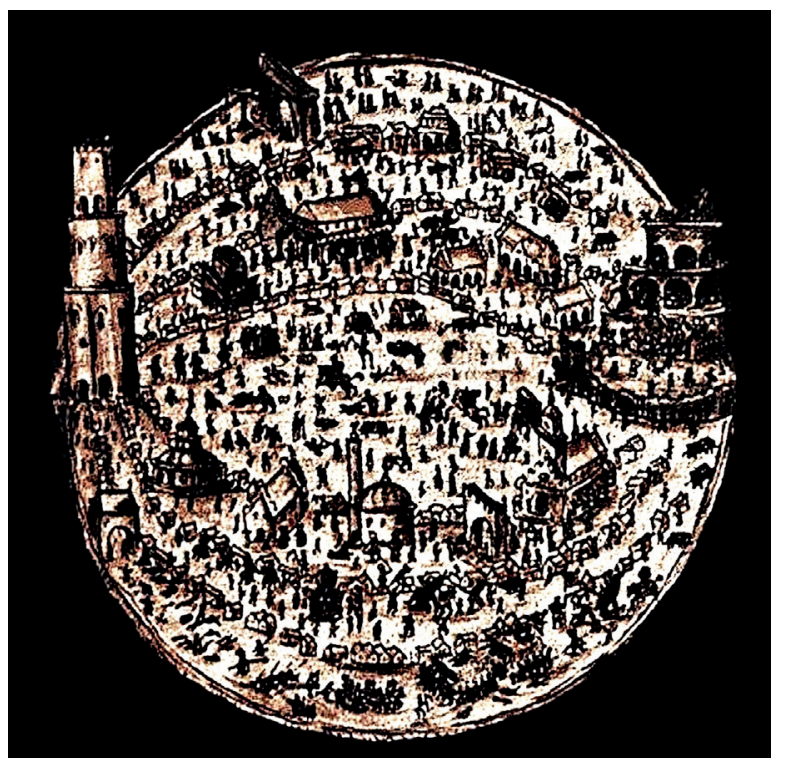

Imagen 1. Dibujo hecho por Comenio para el manuscrito de El laberinto del mundo y el paraíso del corazón en 1623

Fuente: https://laberintodelmundo.wordpress. com [consultado el 25 de enero de 2020]

El Laberinto constituye una de las piezas literarias más caras a las tradiciones moravas y eslovacas que, al igual que muchos de los escritos de su autor, experimentó la persecución de la Contrarreforma, primero, y la sanción de los ilustrados en el umbral de la modernidad, después. Fue escrita en 1623, al inicio de la Guerra de los Treinta Años, cuando las tropas de los Habsburgo sometieron a la nobleza bohemia que regía en Bohemia, Moravia, Silesia y Lusacia. Algún manuscrito se conservó en la biblioteca del Señor de Zerotín, protector de Comenio, a quien se dedica la obra. También experimentó los ambientes del odium theologicum, propios de las luchas entre las Iglesias reformadas y los Contrarreformadores, quienes vetaron su edición; más adelante, se integró en las listas los libros prohibidos a mediados del siglo XVIII (Index publicado en Königgrätz en 1749). En el curso de los siglos, hasta su publicación contemporánea, pocas copias se salvaron de ser destruidas, al conservarse secretamente en las casas de los campesinos y artesanos de la región, pasando de una generación a otra (véase la nota de Lutzow, en Comenius, 1905).

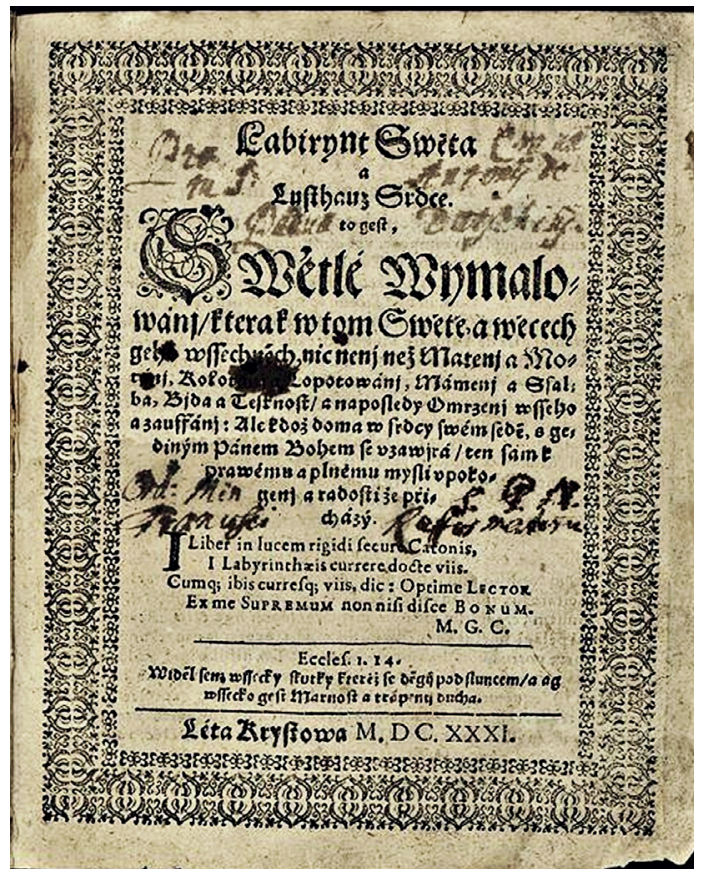

Imagen 2. Portada del libro de J. A. Komenskeho, Labyrint Swěta a Lusthauz Srdce (Laberinto del mundo y paraíso del corazón), publicado en 1631

Fuente: https://commons.wikimedia.org/wiki/File:Labyrint_ světa.jpg?uselang=es [consultado el 25 de enero de 2020].

Su segunda impresión se llevó a cabo en 1631, enriquecida con varios párrafos y los capítulos del XXVIII al XXXV. Una tercera edición, con pequeños añadidos, se publicó en Ámsterdam hacia 1663. Posteriormente, a fines del siglo XIX y en el siglo xx, tuvo diversas ediciones. Para este artículo me baso en la versión inglesa, de 1905, hecha por Lutzow, que integra la tercera edición del siglo XVII.

El Laberinto del mundo corresponde a las obras juveniles de Comenio, pastor de la Iglesia reformada Unitas Fratrum; escrita en uno de los muchos momentos dramáticos de su vida — su existencia clandestina en los rincones más apartados de su región perseguido por su condición herética, la muerte de su esposa y dos pequeños hijos, la conducción de los Hermanos Moravos frente a la amenaza de la persecución política que después se consolidaría como exilio (1618-1622) 一, da cuenta de los conflictos de la región. ${ }^{2}$ Y esta es una de las calas que se puede hacer en el texto, el filón autobiográfico que aporta contenidos históricos del siglo XVII.

2 Frente al vasto programa expansionista de los Habsburgo donde tiene lugar la persecución de las Iglesias reformadas en la región, desencadenantes de la Guerra de los Treinta Años (1618-1648) que concluye cuando se firma la Paz de Westfalia. 
La obra es indudablemente hija de su tiempo, un producto cultural de la época, de la región. También nos habla de las influencias que emigraron a ella: en general, las procedentes de las clásicas utopías del siglo xvi: La ciudad del sol, de Campanella (1602); Utopía, de Moro (1516); Nueva Atlántida, de F. Bacon (1619). Particularmente influyó en Comenio, Johann Valentin Andreae (pastor luterano, 1586-1654), autor de varios escritos atribuidos a los rosacruces: Fama Fraternitatis y Confessio, Peregrinii in patria errores (1618) y la utopía cristiana Republicae Christianopolitanae Descriptio (1619).

Por otro lado, el propósito de los reformadores de hacer accesible la Biblia a los fieles con fines de salvación, al motivar su traducción en lengua vernácula, ofrecía versiones locales que se transformaban en modelos de empleo del lenguaje y de introducción de palabras y giros lingüísticos. Y en el caso del Laberinto también influyó la Biblia de Kralice (Moravia), traducida por la Unitas Fratrum.

En fin, a la cala autobiográfica e histórico-social de la obra, podemos agregar otras que se refieren a los elementos alegóricos y simbólicos con los que la construye su autor. Desde el entramado de estos niveles abordo el análisis general del libro, deteniéndome en algunos pasajes ya sea porque me resultan particularmente sugerentes, ya sea porque contienen claves de interpretación del texto en relación con los propósitos de este trabajo.

\section{Transitar el mundo}

De entrada, el autor se dirige a los lectores cristianos de Bohemia - la obra está escrita en checo- para comunicarles el propósito persuasivo, retórico, convincente que persigue con su escrito:

No es una creación literaria, lector, lo que leerás, aunque cuando pueda parecerse a una ficción. Contiene asuntos ciertos; entendiéndome, lo reconocerás; él, en particular, que tiene algún conocimiento de mi vida y sus peripecias. Principalmente he descrito las contingencias que ya he encontrado en los no muy numerosos años de mi vida, aun cuando también he descrito algunos incidentes que he visto en otros, aspectos relacionados con ellos, y cuya información me fue otorgada. Sin embargo, no he aludido a todos los acontecimientos que me han sobrevenido, en cierto modo por pudor, o porque no sé que enseñanza pueda conferir a otros una narrativa como ésta. (Comenius, 1905, p. 7) ${ }^{3}$

3 Si bien actualmente existen distintas versiones del Laberinto del mundo $(1953,1999,2006,2009)$, en esta lectura se mantiene como referente documental Comenius (1905).
Consecuente con ello, inicia su relato. El argumento: el punto de partida de la narración es el del hombre, en edad de distinguir entre "lo bueno y lo malo" que se dispone a escoger estado y ocupación en la que transcurrirá la vida, con la intención de que ello revista la menor dosis de peligros y violencia y la mayor satisfacción, tranquilidad y bienestar. Con temor a equivocarse o a verse influido y desorientado por los demás, decide ir a ver directamente el mundo, imaginado como ciudad, conforme a la urbanística medieval en uso, para percatarse de "cuántas cosas humanas existían bajo el sol” (p. 10). Al tratar de orientarse por el que sería su camino, le sale al paso un guía - el necesario guía que requieren los peregrinos que transitan por el mundo- para acompañarlo. Se llama Sabelotodo y se apellida Ubicuo; unos cuantos pasos adelante se les une otro guía, la Impudicia, que, por órdenes de la Reina Sabiduría-Vanidad, le da un freno y unos anteojos, para que vea solo lo que le permiten y lo que vea sea tal y como quieren que lo vea (pp. 10-15).

Los tres suben a lo alto de una torre, ${ }^{4} \mathrm{y}$ este es el primer emplazamiento que tiene el Peregrino, como punto de observación y de reflexión, frente al mundo: a la distancia, ante sus ojos aparece una ciudad amurallada, de planta circular - en parte a la manera de La ciudad del sol, obra que también influyó en la obra de Andreae, Republicae Christianopolitae Descriptio (1619) - Sus habitantes son agradables, refinados:

\begin{abstract}
Mientras meditaba — dice-, miré y nos encontramos nosotros mismos (no sé cómo) en una torre muy alta y me pareció que estaba bajo las nubes. Atisbando desde aquí hacia abajo, veo en la tierra un pueblo de apariencia fina y hermosa, y muy amplio, pero en cada dirección podía percibir sus fronteras y límites. Estaba construido en forma de círculo y habilitado con paredes y murallas; en vez de acequia había un valle oscuro, profundo, el que, como me pareció, no contaba con ribera ni lecho. Pero solo encima de la ciudad había luz; ${ }^{5}$ todo alrededor era completa oscuridad. (p. 17)
\end{abstract}

La ciudad, llena de calles y recovecos, con construcciones pequeñas y grandes, estaba divida por una gran calle que corría de este a oeste, emplazada en ambos extremos por puertas: por la primera todos entraban a la vida; por la segunda solo uno podía pasar y, de acuerdo con su destino, a dedicarse a la

4 Como Axis mundi que conecta el cielo con la Tierra.

5 Andreae aboga porque las ciudades estén bien iluminadas para evitar las tinieblas del pecado. 
ocupación que le caía en suerte; ${ }^{6}$ existía una tercera puerta reservada a los elegidos, como veremos más adelante. Había seis calles principales, cuyos grupos y sectores sociales están perfectamente delimitados, de acuerdo con la usanza de las ciudades medievales, dispuestos de acuerdo con las funciones que cada uno de los "estados" desempeñaba: matrimonios, usureros y negociantes, estudiosos e intelectuales, clérigos, magistrados y gobernantes, caballeros y guerreros, cuyos campesinos están ausentes. ${ }^{7}$

Sabelotodo Ubicuo invita al Peregrino a mirar de cerca todo lo que hay en el mundo para decidir su ocupación, de modo que descienden. El Peregrino pasa las dos primeras puertas y empieza a recorrer cada una de las calles y a observar de cerca los distintos estados y ocupaciones. Uno por uno suscita reflexiones y observaciones, azoro y preguntas, que poco a poco lo molestan, lo enfadan y lo decepcionan, por su vanidad, por el engaño y el mal que acarrean tras de sí.

Comenio, narrador y peregrino, recurrentemente entrecruza en la trama narrativa su experiencia y sus vivencias. La descripción de cada uno de los estados comunica episodios personales - sus años de formación, la efervescencia del movimiento Rosacruz que presenció cuando estudiaba en Heidelberg, el naufragio que vivió cuando se dirigía a Inglaterra, las luchas por el poder que vivió en carne propia y que le costaron el exilio de por vida-, episodios de la región gobernada por la corona checa - desmembrada y sometida al poder de los Austrias-, nombres de los protagonistas del momento y de los pensadores reconocidos en Europa de esa época y de otras; también salen a relucir Alejandro el Grande, el Duque de Alba, Poncio Pilato, Loyola, entre muchos otros.

$\mathrm{Al}$ adentrarse en el mundo, lo primero que hace es visitar la gran plaza del mercado, que a la manera del gran teatro del mundo, muestra todas las ocupaciones y los estados que desembocan en ella, todos mezclados en lenguas, naciones, edades, ocupaciones, con atuendos diversos. Hacen distintas cosas, pero las relaciones, de unos con otros en cualquiera de las situaciones, destructivas, están mediadas por la apariencia, por el engaño: cada uno de ellos porta consigo una máscara, que cubre un rostro y un cuerpo

6 Comenio, por convicción teológica, fue partidario de la predestinación.

$7 \quad$ La ciudad de planta circular también está presente en otras creaciones utópicas que fueron muy apreciadas por Comenio, como Civitas Solis, de Tomaso Campanella, que la distribuye en siete círculos concéntricos, y, más próximo a Comenio, la de Johann Valentin Andreae, Christianopolis (1619), que organiza la ciudad-fortaleza en cuatro zonas, asignando a cada una de ellas construcciones y tareas específicas. deforme, con cabezas de cerdo, dientes de perro, orejas de mono y otras tantas facciones de animal, que les dan una apariencia monstruosa.

Y observando a esto atentamente, veo que tanto en sus caras como en sus cuerpos aparecen deformaciones de varios tipos. Casi todas estaban pustulientas, sarnosas o leprosas; y, además, una tenía un labio de cerdo, otra dientes como de perro, otra los cuernos de un buey, otra orejas de burro, otra ojos de basilisco, otra la cola de una zorra, otra las garras de un lobo. A Algunos los vi con un cuello de pavorreal extendido en alto; otros con cascos de caballo y así sucesivamente; la mayor parte tenía similitud con los simios. Asustado, digo: “Aquí me parece que veo monstruos!”. “iQué insolente, exclamó —el guía [Impudicia]—! Mire bien a través de sus espejuelos y verá que son hombres". Pero alguno de los que pasaban escuchó que los había llamado monstruos, permaneció quieto y me gruño, e inclusive se comportó como si me fuera a atacar. Entendiendo entonces que razonar aquí era en vano, permanecí en silencio y pensé para mis adentros: "Si fueran seres humanos, déjalos entonces así, pero para mí, lo que vi, lo vi". Temí entonces que mi guía, con firmeza pudiera quitarme mis espejuelos y así me desorientara, por lo tanto, decidí callar [...]. Me di cuenta como muchos manejan estas máscaras artificiosamente, removiéndolas para volver a colocarlas después, de manera que pudieran darse un talante diferente a sí mismos, siempre que consideraran que esto iba en su beneficio. (p. 24)

Más allá de compartir la sensibilidad aficionada al tema del engaño, la ilusión, la distorsión de la realidad, Comenio plantea una de sus convicciones filosófico-teológicas, que es constante en el desarrollo de la obra: la concepción del hombre a partir de dos principios antitéticos, el Homo animalis y el Homo spiritualis, que habrían de resolverse mediante la intervención de la tarea redentora del cristianismo $y$, supuestamente, mediante la educación, en el paradigma de la perfección del ser humano. A través del recorrido por el laberinto del mundo, el autor quiere convencer al lector de que en todo lo que sucede en el ámbito mundano, predomina el Homo animalis, carnalis, bestialis; puede decirse que incluso la primera parte de la obra, "El laberinto del mundo propiamente dicho", es el escenario ad hoc del Homo animalis.

El espejo, los binoculares, los juegos de lentes son recurrentes para distinguir la verdad del engaño, lo que subsiste atrás de la realidad deformada, como sucede con las distintas personas que se muestran en la plaza del mercado, donde se vuelven visibles sus verdaderos rasgos detrás de las máscaras con las que se cubren. 
Otro de los temas recurrentes en la literatura de la época, que se introduce en la plaza del mercado, es el de la alegoría de la muerte, que hiere con sus flechas a quien se le ocurre, sin distinción de edades, estados, posición social, recordándoles a todos, en voz alta, que son mortales. Pero ninguno de ellos, en su confusión, la escucha hasta que, herido por ella, cae por tierra. ${ }^{8}$

A partir de la plaza del mercado, el Peregrino empieza a recorrer todas las calles y callejones de los distintos "estados" y de cada una de las profesiones y ocupaciones que en ellos se realizan; ve los conflictos, las pugnas, las injusticias, los engaños; reflexiona sobre ellos siempre desde una perspectiva moralizadora, didáctica, que cumple con su propósito de mostrar al lector lo que de mal, de desorden, de confusión, de caos existe en el mundo para después contrastarlo con el Sumo Bien.

Traigo a colación, pues me resultan muy sugerentes en relación con las comunidades académicas, algunos pasajes del Capítulo x "El Peregrino examina el estado de los hombres de estudio", que remiten a sus años formativos.

Entonces llegamos a la entrada que llamaban Disciplina [...]; y esa era larga, estrecha y oscura, llena de guardias armados a los cuales cada uno de los que deseaban pasar a la calle de los doctos, tenían que declararse pidiéndoles que lo acompañaran. Vi, pues, que muchedumbres de gente, especialmente jóvenes, llegaban y en seguida se les sometía a diferentes, amargos, exámenes. El más importante para cada uno era el de qué bolsillo, qué asentaderas, qué cabeza, qué cerebro (según el moco), y qué cuero traía. Si la cabeza era de acero, y los sesos en ella de mercurio, las asentaderas de plomo, el cuero de hierro y el bolsillo de oro, lo alababan y gustosamente lo conducían adelante [...]. Si alguno no tiene la cabeza de acero, se le rompe; si no tiene cerebro líquido adentro, no tendrá en él un espejo; si no tiene cuerpo de hojalata, no soportará las transformaciones de la educación; si no tiene asentaderas de plomo, no empolla nada, lo desparrama todo; y sin bolsillo de oro ¿cómo pagaría el tiempo a los maestros vivos y muertos? ¿0 es que piensas que tamañas cosas pueden llegar gratis?

\section{$[\cdots]$}

8 "Por último vi a la Muerte, acechando por todos lados entre ellos. Estaba provista de una guadaña afilada y con un arco y flechas, que con voz poderosa exhortó a todos a recordar que eran mortales; pero ninguno atendió a su llamado; ninguno hizo el menor caso de sus desatinos y fechorías. Entonces, ajustando las flechas se las arrojó a la gente en todas direcciones derrumbando a algunos, jóvenes o viejos, pobres o ricos, sabios o ignorantes, sin distinción, sucumbieron" (p. 29). Otra de las alegorías muy logradas es la de la Fortuna en el capítulo xxIV y en otros episodios (pp. 146 y ss.)
Después al penetrar más adelante en la entrada, veo que cada uno de los guardias se daba el trabajo de tomar a uno o más de los que entraban, y conduciéndolos les soplaba algo en las orejas, les estregaba los ojos, les limpiaba la nariz y ventanillas con vapor, les sacaba la lengua y se las recortaba, les abría, les cerraba y les descomponía las manos y los dedos, y no sé que otras cosas más les hacía. Algunos hasta trataban de agujerearles las cabezas y verterles algo adentro. Al verme horrorizado ante todo esto, el guía me dijo: No te extrañes, los doctos tienen que tener diferentes manos, lenguas, ojos, orejas, sesos y todos los sentidos internos y externos, tienen que poseerlos diferentes de la clase necia de la gente; por lo tanto, se forman de nuevo aquí, y eso no puede ser sin faena ni repugnancia.

[...]

Entonces me introduce en una plazuela [donde se reúnen médicos, jurisprudentes, filósofos y teólogos], y he aquí que nubes de estudiantes y maestros, doctores, sacerdotes, tanto jóvenes como con canas, hablaban y discutían entre sí formando grupos, mientras algunos se apretaban en algún rincón para evitar la vista de los otros. Algunos [...] tenían ojos y no tenían lengua; otros tenían lengua y no tenían ojos; otros, nada más que orejas, sin ojo ni lengua, etc. Así llegué a comprender que aquí también moraban las insuficiencias. (pp. 57-58)

Durante su recorrido el Peregrino pasa por los más diversos estados de ánimo, experimenta distintas emociones. Se va dando cuenta de que su deseo de saber y su curiosidad no se sacian con nada de lo que va mirando; por el contrario, cada vez se decepciona más del mundo.

Comenio, estudioso de Nicolás de Cusa (14011464), e influido por su célebre De docta ignorantia, se plantea el problema de los límites humanos del conocimiento, ante lo cual más vale refugiarse en una docta ignorancia, que es un "saber que no se sabe".

El clímax, y desenlace, de la primera parte del Laberinto se da cuando el Peregrino visita el Palacio donde habita Sabiduría, la Reina del Mundo. La principal puerta hacia el castillo es la que conduce a la virtud, pero es difícil encontrarla entre otras entradas, tales como Hipocresía, Injusticia, Violencia y algunas más.

En el castillo se prepara un gran acontecimiento, pues Salomón llega, acompañado de una multitud de amigos y servidores, para tomar por esposa a Sabiduría (p. 172). Pero, poco a poco, se da cuenta de que los que gobiernan ese reino son los causantes de los distintos tipos de desórdenes que afectan al mundo (pp. 175 y ss.). Frente al desfile de todos ellos, Salo- 
món desenmascara la vanidad y el engaño del mundo, gritando a los cuatro vientos "Vanidad de vanidades, todo es vanidad" (Eclesiastés, 1, 2, 15). ${ }^{9}$ La Reina del Mundo, ahora con un rostro terrible y deforme, desencadena la persecución, captura, tortura y matanza de la multitud que acompañaba a Salomón. El Peregrino aterrorizado quiere escapar del mundo y prefiere morir antes que seguir presenciando la corrupción, la crueldad. Impudicia desaparece y Sabelotodo detrás de él. Desesperado, perdido en el laberinto, clama: "¡Oh Dios, Dios, Dios! ¡Dios, si tú eres un Dios, ten misericordia del desdichado de mí!" (p. 198).

Una voz misteriosa le ordena: “¡Regresa!”, “Regresa!”, "Regresa desde donde has partido, a la casa de tu corazón, y entonces cierra las puertas tras de ti" (p. 199). Es a partir de entonces cuando empezará a manifestarse plenamente la vida del ser humano como Homo spiritualis. ${ }^{10}$

\section{El viaje interior de Comenio}

El Peregrino obedece. En su interior todo es oscuridad, es desolación y deterioro. Poco a poco aparece una luz brillante, con la imagen de un hombre con el esplendor de Dios, que se le acerca: "Vi que andabas errante y no he querido esperar más, hijo mío. Por eso te he conducido a ti mismo, al fondo de tu corazón". Y para que el Peregrino pueda ver el mundo en su correcta perspectiva, recibe unos anteojos nuevos: ya no los de la decepción ni del engaño, sino que "la montura era la palabra de Dios, los cristales el Espíritu Santo" (pp. 202 y ss.).

Se celebran las bodas místicas entre el alma y Dios, la única forma posible para que el ser humano alcance la perfección. Y, a partir de ahí, Cristo se transforma en su consejero, su guía y su protector (p. 207). Ahora el recorrido se da en lo que serían las sociedades regidas por Dios: justas, verdaderas, unidas, amorosas, abundantes, libres, pacíficas, luminosas, ordenadas por la razón y por el sentido de comunidad. La misma Muerte es la antítesis de la del mundo; en ropaje de Cristo, acoge amorosamente a cada uno. La Iglesia se presenta como lo contrario al mundo. Dentro de la cristiandad, en la alegoría de un gran templo con numerosas capillas laterales que equivalen a las distintas Iglesias reformadas y no reformadas,

9 En el curso de los siglos, la asociación de Salomón con el laberinto ha sido muy frecuente.

10 En las ediciones de los años posteriores a Comenio, a partir del capítulo xxxviI, "The Pilgrim finds his way", se marcó la segunda parte del Laberinto, el Paraíso del corazón. En las primeras ediciones esto no era así. dominan los "verdaderos cristianos", que representan la Hermandad Morava a la que pertenecía Comenio (Filoramo, 1993).

Finalmente, después de sus últimos recorridos guiado por Cristo, el Peregrino es recibido en la casa del mismísimo Dios, y, en una visión apocalíptica, se le revela sentado en un trono de jaspe y rodeado por una multitud de ángeles. Le comunica:

\section{Siéntete muy contento y regocíjate ya que tu nombre se encuentra entre aquellos elegidos; si me rindes culto serás uno de ellos [...]. Espera en el mundo mientras te deje en él, como peregrino, forastero, extranjero, huésped; pero permanece conmigo como uno más de mi hogar. (p. 254)}

La obra concluye con una oración que el Peregrino dirige a Dios, plena de reconocimiento y de mística entrega, donde le agradece el haberlo "guiado en su camino y conducido a través de la lúgubre oscuridad del mundo hacia la luz eterna" (p. 257). ${ }^{11}$

\section{El sentido del laberinto en Comenio}

¿Desde dónde habla el autor?, ¿qué lo obsesiona?, ¿cuál es el sentido de sus recorridos laberínticos?, ¿qué se le revela en el centro? Aproximarnos a ello, desde la perspectiva de la hermenéutica simbólica (Durand, 2007; Ortiz-Osés y Lanceros, 1997; Solares, 2001), necesariamente nos conduce a confrontar las vías del conocimiento bosquejadas desde la Grecia clásica: unas, apelando a la razón, a las verdades positivas, al orden, a la certeza de la transparencia; otras, a la imaginación, a lo mistérico, a lo hermético, a lo complejo. Según este enfoque, la existencia constituye un texto o un contexto que plantea la presencia de lo no dicho, de lo latente, de lo implícito, de lo apenas intuible, que requiere, para aprehenderse, de un acercamiento simbólico ya que no basta con lo empírico ni con lo fenoménico. Esto nos permite ampliar nuestros horizontes de sentido.

Así, el laberinto se devela como una constante en la vida humana que plantea la condición de su secreto. Como arquetipo, atraviesa la historia de la humanidad recreando su sentido entre los diversos grupos sociales y

11 Comenio tiene una gran influencia del pensamiento místico alemán, particularmente de Jacob Böhme y de Eckart; considera que Dios es el centro de todas las cosas y se define por una actitud antiintelectualista que rechaza la supuesta transparencia del cognoscitivo. Particularmente en esta obra asume, como vía privilegiada de conocimiento, la visión misteriosa a la que se abandona. Seguidor de Agustín de Hipona, exalta la superioridad de la vista interior y asume que la educación, la verdadera transformación, procede de la iluminación interior que conduce a descubrir en sí mismo la imagen divina. Esta visión interior es afín a la revelación y permite superar el engaño presente en el mundo. 
culturas - como ya hemos dicho-. Pero hay elementos recurrentes que es posible reconocer en cualquiera de sus manifestaciones: es un símbolo que expresa una forma de defensa de algo muy valioso o misterioso; el centro difícilmente se logra penetrar con facilidad, y por lo mismo no es accesible a todos; el centro se vincula directamente con el principio de la creación y recreación de la vida. El laberinto representa, por tanto, el sentido de la aventura de la vida, de los peligros que acechan; también los diversos rostros de los peligros que entrañan muerte, la búsqueda de las vías de salida. ${ }^{12}$ Expresa, además, un constante tránsito, etapas que se van superando en las que está presente el sentido de las pruebas, aparentes treguas que impelen a afrontar nuevamente los peligros del perfeccionamiento. Existe en los seres humanos como huella arquetípica de la condición transitoria de la vida, de la forma en que afronta la existencia, cómo resuelve sus retos.

\section{Dice M. Brion:}

Para el viajero que penetra en el laberinto, la meta reside en alcanzar la sala central, la cripta de los misterios. Pero, no bien ha llegado a ella, debe salir y volver al mundo exterior, o sea, pasar a un nuevo nacimiento: ese es el contenido de todas las religiones mistéricas y de todas las sectas que consideran el viaje en el laberinto como el proceso insoslayable de las metamorfosis de las que surge el hombre nuevo. (citado en Santarcangeli, 1997, p. 153)

Y es esta la retórica de Comenio, teólogo y pastor de la pequeña hermandad de la Iglesia Checa Reformada, comprometido con la regeneración de los hombres, de las sociedades, de los saberes: quiere convencer al lector cristiano de los peligros que entraña el mundo, de su permanente condición de engaño y deterioro, de la fragilidad del ser humano para superarlos, de la necesidad de acceder a las verdades supremas.

Así, el Peregrino con sus guías y sus artefactos - anteojos y freno- es el mismo ser humano que se desdobla en impudicia, que engaña y se engaña, $\mathrm{y}$ en arrogancia de querer saber todo, de creer que lo puede saber - el tema de la docta ignorantia del Cusano- $-{ }^{13}$ Una noción de naturaleza humana que

12 Los estudios de abundantes materiales procedentes de diversas regiones relacionados con las más antiguas religiones lo vinculan con la imagen de la Madre Tierra y con la gestación de la vida en la matriz humana, que se transforma en el centro sagrado donde se cumple el misterio de la vida, lugar de difícil acceso (Santarcangeli, 1997).

13 Nicolás de Cusa (1401-1464), en su célebre obra De docta ignorantia, plantea el problema de los límites humanos del conocimiento, ante lo cual invita a refugiarse en una docta ignorancia, que es un "saber que no se sabe"; con ello, sugiere replegarse en la experiencia mística. comprende dos principios antitéticos, en conflicto permanente, el Homo animalis y el Homo spiritualis, sustenta la tensión que trama los movimientos del principal protagonista, sus desplazamientos en medio de los peligros que lo acechan en lo que sería el mundo terrenal, exterior, y la revelación del mundo interior, espiritual; también se desdobla en dos emplazamientos, la ciudad terrenal y la ciudad celestial. En medio de ello transcurre el iter perfectionis, hecho de muertes y renacimientos constantes, de pruebas iniciáticas para los elegidos, que requiere una respuesta total del hombre total, cuya verdadera condición yace oculta en espera de ser revelada. ${ }^{14}$

La primera parte del relato nos comunica la condición épica de la vida del Peregrino, la búsqueda de su propio camino. Sin embargo, la solución de la obra no necesariamente se resuelve en drama, en movimiento, sino en la descripción de lo que se observa, en lo que ya se sabía de antemano, y sobre lo que se advierte, se amonesta; siempre se establece distancia con el mundo, ya sea desde la altura de la torre, ya sea con los anteojos. El Peregrino no se involucra de lleno, no afronta los peligros, no los embate. A diferencia del héroe griego, que adquiere la condición de héroe por el simple hecho de atreverse a salir de la casa, solo los contempla, reflexiona sobre ellos, descubre lo que hay detrás de las apariencias, se desencanta.

Su angustia aumenta en la medida en que más observa, y el optar por un camino cada vez se complica más, los vericuetos resultan más tortuosos y destructivos - recordemos que Comenio también es un hombre de sensibilidad manierista-, de modo que en vez de ganar en claridad, se confunde y se desilusiona del mundo, da curso a su sensibilidad trágica. La herida está provocada por la inautenticidad de la vida, la ausencia de compasión. El gran problema de la vida en el mundo terrenal resulta ser que, a la manera de una tierra baldía, estéril, nadie vive una vida plena, acorde con la armonía del cosmos, con los niveles de mayor perfección humana. Es entonces cuando está en condiciones de alcanzar el centro del laberinto. ${ }^{15}$

14 Una importante componente gnóstica se combina con la mística: el gnosticismo se funda en la fragilidad de la existencia humana, pues el hombre, partícipe de la luz divina, a causa de un error se precipita en un mundo de tinieblas que le es hostil y lo lacera olvidando su lugar de origen. En medio de la búsqueda angustiosa de la gnosis, del conocimiento verdadero que le dé conciencia de su identidad, surge un Salvador que le revela su origen y su destino, con lo cual puede retornar a la Patria.

15 Desde la perspectiva simbólica no necesariamente es el cielo; también puede ser el infierno. 
Al atravesar la puerta, pasa a otro plano de la vida que lo salva del caos del mundo. Se encuentra en el centro, donde ya no hay pruebas ni peligros, pues ya está en el lugar donde se lleva a cabo la transformación, el renacimiento, la muerte del estadio anterior. De la oscuridad paulatinamente emerge la luz, surge la iluminación. El centro es el Axis mundi (Eliade, 1992), lugar donde convergen los opuestos, de donde surge todo.

¿Qué experimenta el Peregrino al llegar al Centro del laberinto? En principio transita del conocimiento del mundo terrenal, exterior, al conocimiento de su mundo interior, a conocerse a sí mismo y a reconocer su papel en el mundo. Está decidido a habitar su corazón; se encuentra en el umbral de la vida plena donde puede curar su herida con amor. Al experimentar la compasión, es cuando nace Cristo en su interior, que es en realidad el ser espiritual que hay dentro de cada ser humano. Ahí lo recibe Cristo, lo acoge Dios. Le es revelado su lugar en el universo, el secreto de una vida plena, armoniosa. ${ }^{16}$ El eco de las soluciones laberínticas medievales - que ubican la ciudad sagrada de Jerusalén en el centro ${ }^{17}$-, se percibe al colocar en este centro comeniano del siglo XVII la vida espiritual, la ciudad celestial, y a la propia Santa Ecclesia donde mora Cristo. "Los polos de las esferas coinciden con el centro, que es Dios", dice Nicolás de Cusa. Y esto lo sabía muy bien el autor del Laberinto; algunos de sus escritos teológicos, como Centrum Securitatis, planteaban esta convicción.

En el centro, el Peregrino encuentra la salvación; ahí existe el principio de redención, de recuperación del paraíso. Está en condiciones de ser redimido y de

16 Favorecer las condiciones que hagan posible la armonía y el espíritu de universalidad es una constante en la vida de Comenio y atraviesa su empresa política y social, lo cual ha hecho que se le vincule con colegios y hermandades a menudo marcadas por el pensamiento masónico. Así, puede mencionarse los Rosacruces, entramados en la masonería especulativa que derivan en el krausismo, donde Basedow, Pestalozzi y Froebel coinciden en la perspectiva de formación humana. Krausistas, froebelianos y Lehonardi, discípulo de Krause (1781-1832), a finales del siglo XIX, volverán los ojos a Comenio para fundamentar un vasto programa educativo. El movimiento generará "asociaciones de la humanidad", "logias de la humanidad abiertas a todos", "asociaciones de Comenius", "asociaciones de Krause" y "asociaciones de Froebel", orientadas a la educación de la humanidad, a través de las escuelas para la vida (Álvarez, 1996; Ureña, 1990).

17 La ciudad de Creta, famosa por el laberinto con su Minotauro fue olvidada por los romanos, y en su lugar Troya ocupó el centro del laberinto, por su dificultad de acceder a ella, por los rodeos y los peligros que había que vencer. Pero los cristianos de la Edad Media no podían aceptar que una ciudad pagana estuviera en el centro de su laberinto. Ese lugar le correspondió a una ciudad sagrada como Jerusalén, destino de las peregrinaciones (Santarcangeli, 1997). salvar al mundo. Es su mandala, ${ }^{18}$ cuya simbología circular da cuenta de dos movimientos complementarios en los que converge el ser humano y el cosmos. El círculo se desdobla en dos planos, como nos dice Chevalier y Gheerbrant:

por su radiación horizontal puede considerarse un microcosmos que contiene en sí todas las virtualidades del universo, y en su radiación vertical, un lugar de pasaje, el cenáculo de las iniciaciones, la vía entre los planos celeste, terreno e infernal del mundo, el umbral de la liberación y en consecuencia de ruptura. (1991, p.v; énfasis añadidos)

El segundo plano simbólico del círculo, el de la radiación vertical, nos remite a la condición del laberinto que implica también un proceso iniciático; hay que vencer obstáculos, hay que superar peligros para llegar al centro, hay que sanar y curar las heridas provocadas por el mundo, hay que asumir la propia vida, y al tomar en las propias manos el destino, comprometerse con la misión que cada uno tiene en el mundo. No todos logran salir sanos y salvos de este proceso; son pocos. Muchos quedan por el camino, perdidos entre los recovecos y encrucijadas.

Esto es así. El Peregrino que logró vencer los obstáculos y tentaciones para llegar al centro en realidad es un elegido. No todos llegan al lugar de lo sagrado, de la revelación de los arcanos del Universo, el lugar donde cristaliza la Gran Transformación, el perfeccionamiento del hombre interior, el lugar donde el Homo spiritualis derrota al Homo animalis, donde la Ciudad Terrestre es desplazada por la Ciudad Celestial. El tránsito de las tinieblas a la luz confirma su nueva condición de consagrado. ${ }^{19}$

El Peregrino comeniano, fortalecido, renovado, no permaneció en el centro del Laberinto. Regresó a completar su tránsito por la Tierra. Entonces ya comprendía lo que era el mundo, ya había encontrado su camino, el sentido de su vida; consagrarse a las reformas religiosas desde su pequeña comunidad checa, la Unitas Fratrum.

18 “Mandala es el nombre sánscrito de 'círculo', pero un círculo coordinado o designado simbólicamente de tal modo que sea el significado de un orden cósmico" (Campbell, 1991, p. 298).

19 Comenio, el autor, también es un hombre en transición que se ubica en el umbral de la modernidad. Vive la crisis de la transición, participa de la mentalidad manierista pero también de las creencias y conocimientos gnósticos, milenaristas, místicos y alquímicos particularmente desarrollados en su región desde tiempos de la corte de Rodolfo II. 


\section{A modo de epílogo}

Finalmente, ¿cuál pudo ser el sentido más profundo de los recorridos laberínticos de nuestro autor? ¿Qué enseñanzas podemos recoger para nuestros tiempos? A lo largo de la vida Comenio experimentó, a diversos niveles, el complejo momento de reordenamiento social de los siglos XVI y XVII, propios de él, de su momento, de su sociedad, en medio de circunstancias diversas a las nuestras. No obstante, es de ello de donde podemos abrevar procesos de reflexión para nuestro mundo, para nuestros tiempos, para nuestras circunstancias.

Vivimos tiempos de crisis, de incertidumbre, de temor e inseguridad frente a lo venidero, frente a un nuevo orden social que se avizora. Experimentamos las crisis sistémicas, totales, que vuelve visibles la pandemia inscrita en la covid-19, en las que se perciben indicios de las fracturas de la economía de mercado y del proyecto político neoliberal en que esta se inscribe. El modelo de desarrollo por el que se venía pugnando, aun contra nuestra voluntad, hizo crisis: la óptica de mercado mediando nuestras relaciones, nuestra vida cotidiana, el consumismo, el individualismo y la competencia, el adelgazamiento del Estado, la exacerbación de la pobreza extrema y de la riqueza extrema, la pérdida de un proyecto social extensivo a amplios sectores, la sobreexplotación de la tierra, el calor sofocante y el frío extremo, las inundaciones, los sismos de distinta magnitud, la privatización de la educación, del sistema sanitario, del agua, de la luz (Amedeo, 2020; Boff, 2020; Klein, 2019; Touraine, 2020). ¿Será posible que el capitalismo salvaje pueda persistir?

El 2019 fue un año convulso en distintas esferas y regiones (Barcelona, París, Hong Kong, Irán, solo por mencionar algunas), pleno de revueltas, de protestas, de manifestaciones, de asesinatos... El 2020 inició con la emboscada en la que perdió la vida el general iraní Qassem Soleimani. Por otra parte, en la vida de cada día experimentamos el agobio de distintas presiones, exigencias y privaciones en amplios sectores de la sociedad. En este horizonte surgió la pandemia ocasionada por el coronavirus y el mundo se detuvo de repente: las escuelas, los almacenes, las plazas públicas se cerraron; las personas, las que tuvieron condiciones para hacerlo, se encerraron en sus casas presas del pánico colectivo a contagiarse y sucumbir al mal, pero no solo eso, se implementaron medidas de control social, bajo el título de lo que el filósofo italiano Giorgio Agamben (2010) ha calificado como "estado de excepción" con la inherente restricción de libertades y control de los mínimos movimientos personales, con la exacerbación de racismos y xeno- fobias, con el establecimiento de fronteras y cotos a nivel local, regional, nacional e internacional, que ni Foucault hubiera podido imaginar

La información que circula no deja de ser contradictoria: oscila entre restarle gravedad al asunto de la epidemia de alcances globales, contextuarla históricamente a partir de otras epidemias que han asolado al mundo, plantear la baja tasa de mortalidad, sus efectos no necesariamente letales y el señalamiento del factor industria farmacéutica combinado con una óptica de mercado soterrada que propone la panacea para todo mal; por otro lado lado, el aislamiento, la exigencia de eliminar toda forma de contacto social, el pánico colectivo auspiciado y fortalecido por las redes, por los medios de comunicación, por las autoridades que, hasta la obsesión, señalan las cifras de muertos que aumentan día a día, la insuficiencia de los servicios sanitarios e incluso la previsión de fosas cavadas para recibir los cadáveres.... ¿Quién entiende?

La situación nos coloca en una encrucijada, mediada por el estancamiento económico y el agotamiento del actual orden mundial: la rigidización de las formas de control social en la perspectiva de los estados totalitarios, o bien la posibilidad de construir nuevas formas de convivencia y de solidaridad social que conduzcan a pensarse y a experimentarse como parte de la comunidad global, no consumista, impulsando otro tipo de valores, más consciente de sus relaciones con el conjunto del universo donde será posible construir un nuevo sentido de la vida. ${ }^{20}$ Pensemos, como lo hizo Comenio en su momento, que el horizonte de posibilidades está abierto, que podremos recuperar lo humano del ser humano...

20 El filósofo italiano Berardi hace una aguda crítica en relación con la crisis del momento actual, donde tal parece que quedamos atrapados en una maraña de automatismos tecnológicos y lingüísticos que impactan el terreno de las finanzas, la competencia desbordada, la escalada militarista. Enfrentamos un proceso poshumano y antihumano desbordado capaz de anular el pensamiento crítico en el que, no obstante, el pensamiento humanista es el único que nos ofrece posibilidades de recuperar el futuro (Berardi, 2019). 


\section{Referencias}

Agamben, G. (2010). Estado de excepción. Homo sacer II, 1 (A. Gimeno Cuspinera, trad.). Pre-textos.

Aguirre Lora, M. E. (2001). Calidoscopios comenianos II Acercamientos a una hermenéutica de la cultura. UNAMCESU; Plaza y Valdés.

Aguirre Lora, M. E. (2016). “Comenio, Amós”. En A. M. Salmerón, B. F. Trujillo, A. Rodríguez y M. de la Torre (coords.). Diccionario iberoamericano de filosofía de la educación. Fondo de Cultura Económica.

Aguirre Lora, M. E. (2019). Un jardín para la infancia. Metáfora comeniana recreada en nuestros tiempos. Historia y Memoria de la Educación, 9, 319-341.

Álvarez Lázaro, P. (1996). La masonería, escuela de formación del ciudadano. La educación interna de los masones españoles en el último tercio del siglo XIX. Universidad Pontificia Comillas.

Andreae, J. V. (1619). Republicae Christianopolitanae Descriptio (filmina de la Biblioteca Nacional de Praha, Sección Incunables).

Amedeo, P. (ed.). (2020). Sopa de Wuhan. Pensamiento contemporáneo en tiempo de pandemias. Buenos Aires: Aislamiento Social Preventivo y Obligatorio.

Bayle, P. (1740). Dictionnaire historique et critique (t. I, $16 .{ }^{\text {a }}$ ed.). Chez Jean Louis Brandmüller. (Original publicado en 1695).

Berardi, F. B. (2019). Futurabilidad. La era de la impotencia y el horizonte de la posibilidad. Caja Negra.

Boff, L. (2020, 21 de abril). Coronavirus: el perfecto desastre para el capitalismo del desastre. La columna semanal de Leonardo Boff. https://www.servicioskoinonia.org/ boff/articulo.php?num=974

Boff, L. (2020, 5 de abril). El coronavirus despierta en nosotros lo humano. La columna semanal de Leonardo Boff. https://www.servicioskoinonia.org/boff/articulo. php?num $=977$

Campbell, J. (1991). El poder del mito (César Aira, trad.). Emecé.

Chevalier, J. y A. Gheerbrant (1991). Diccionario de los símbolos (3. a ed., M. Silvar y A. Rodríguez, trads.). Herder.

Comenio, J. A. (1971). Didáctica magna. Porrúa.

Comenio, J. A. (1999). El laberinto del mundo y el paraíso del corazón. Epsilon.
Comenio, J. A. (2006). El laberinto del mundo y el paraíso del corazón (H. Voldan, trad. y J. Blahoslav Čapek, comentario crítico). Ekumene Comenius Cultural Center, Ars Bohemiae.

Comenius, J. A. (1905). Laberynth of the world and the paradise of the heart (C. Lutzow, trad. y ed.). J. M. Dent and Aldine House.

Comenius, J. A. (1992). Pampedia. Universidad Nacional de Educación a Distancia.

Comenio, J. A. (1993). El mundo sensible en imágenes. Consejo Nacional de Ciencia y Tecnología; Miguel Ángel Porrúa.

Comenius, J. A. (2009). El laberinto del mundo y el paraíso del corazón (M. E. Aguirre, ed.). Biblioteca Nueva, Memoria y Crítica de la Educación.

Czyzevsky, D. (1953). Comenius Labyrinth of the world: Its themes and their sources. University of Harvard.

Durand, G. (2007). La imaginación simbólica (M. Roizman, trad.). Amorrortu.

Echeverría, B. (1988). La modernidad de lo barroco. Era

Eliade, M. (1992). Imágenes y símbolos (C. Castro, trad.). Taurus.

Filoramo, Giovanni (1993). L'atessa della fine. Storia de la gnosi. Laterza.

Klein. E. (2019). Postdevelopment in practice: alternatives, economies, ontologies. Routledge.

Ortiz-Osés, A. y Lanceros, P. (coords.). (1997). Diccionario de hermenéutica; una obra interdisciplinar para las ciencias humanas. Universidad de Deusto.

Santarcangeli, P. (1997). El libro de los laberintos. Historia de un mito y de un símbolo (C. Palma, trad.). Siruela.

Solares, B. (coord.). (2001). Los lenguajes del símbolo. Investigaciones de hermenéutica simbólica. Centro Regional de Investigaciones Multidisciplinarias, UNAM; Anthropos.

Touraine, A. (2020). Esta crisis va a empujar hacia arriba a los cuidadores. Entrevista con Marc Bassets. El País.

Ureña, E. M. (1990). Orígenes del krausofröbelismo y masonería. Historia de la Educación. Revista Interuniversitaria, (9), 43-62. 